Brain, Behavior and Evolution
Brain Behav Evol 2012;80:15-25

DOI: $\underline{10.1159 / 000338324}$
Received: July 7, 2011

Returned for revision: July 26, 2011

Accepted after revision: March 22, 2012

Published online: June 22, 2012

\title{
Evolutionary Change in the Brain Size of Bats
}

\author{
Lu Yao $^{\text {a }}$ J.-P. Brown ${ }^{a}$ Marco Stampanoni ${ }^{b, c}$ Federica Marone ${ }^{b}$ Karin Isler $^{d}$ \\ Robert D. Martin ${ }^{a}$ \\ ${ }^{a}$ Department of Anthropology, The Field Museum, Chicago, III., USA; b Swiss Light Source, Paul Scherrer Institut, \\ Villigen, ' Institute for Biomedical Engineering, University and ETH Zürich, and ${ }^{\mathrm{d}}$ Anthropological Institute and \\ Museum, Universität Zürich-Irchel, Zurich, Switzerland
}

\section{Key Words}

Bats $\cdot$ Brain size reduction $\cdot$ Chiroptera $\cdot$ Evolutionary

trend · Fossil · Hipposideros - Synchrotron radiation X-ray

tomographic microscopy $\cdot$ Virtual endocasts

\begin{abstract}
It has been widely recognized that mammal brain size predominantly increases over evolutionary time. Safi et al. [Biol Lett 2005;1:283-286] questioned the generality of this trend, arguing that brain size evolution among bats involved reduction in multiple lineages as well as enlargement in others. Our study explored the direction of change in the evolution of bat brain size by estimating brain volume in fossil bats, using synchrotron radiation X-ray tomographic microscopy. Virtual endocasts were generated from 2 Hipposideros species: 3 specimens of Oligocene Hipposideros schlosseri $(\sim 35 \mathrm{Ma})$ and 3 of Miocene Hipposideros bouziguensis $(\sim 20$ Ma). Upper molar tooth dimensions ( $\mathrm{M}^{2}$ length $\times$ width) collected for 43 extant insectivorous bat species were used to derive empirical formulae to estimate body mass in the fossil bats. Brain size was found to be relatively smaller in the fossil bats than in the average extant bat both with raw data and after allowing for phylogenetic inertia. Phylogenetic modeling of ancestral relative brain size with and without fossil bats confirmed a general trend towards evolutionary increase in this bat lineage.

Copyright $\odot 2012$ S. Karger AG, Basel
\end{abstract}

\section{Introduction}

Jerison's classic 1973 text on evolution of the brain in vertebrates provided numerous examples clearly documenting a general increase in brain size over time in many mammal lineages. He confirmed an overall trend in the fossil record that had been progressively recognized since the time of Marsh [1874]. More recent studies of large data sets have clearly confirmed Jerison's interpretation for 3 orders of mammals: Primates [Martin, 1990; Martin and Isler, 2010], Cetacea [Marino et al., 2004], and Carnivora [Finarelli and Flynn, 2007]. Moreover, the same trend has now been confirmed with respect to very early mammals [Rowe et al., 2011].

It was long thought that brain size is related to body surface area [Jerison, 1973], but it was subsequently proposed that brain size may instead be linked to metabolic turnover [Martin, 1981; Mink et al., 1981; Armstrong, 1983]. This alternative interpretation was proposed partly because brain tissue has a high energetic cost and partly because scaling of brain size parallels scaling in basal metabolic rate (BMR) rather than that of surface area. However, relative brain size shows a five-fold range of variation on either side of the average condition in mammals. Such wide variation greatly exceeds the relatively modest two-fold variation in adult BMR relative to the average condition. Therefore, brain size must be influ-

\section{KARGER}

Fax +41613061234

E-Mail karger@karger.ch

www.karger.com
(C) 2012 S. Karger AG, Basel

0006-8977/12/0801-0015\$38.00/0

Accessible online at:

www.karger.com/bbe
Prof. Robert D. Martin

Department of Anthropology

The Field Museum

Chicago, IL 60605 (USA)

Tel. +1 312665 7809, E-Mail rdmartin@ fieldmuseum.org 
enced by other factors in addition to BMR, and availability of resources during early development is a prime candidate. Recognition of this led to formulation of the Maternal Energy Hypothesis [Martin, 1996; Martin and Isler, 2010]. According to this hypothesis, a larger brain reflects an increase in maternal resources devoted to the developing offspring. Over evolutionary time, a general trend towards an increased level and efficiency of commitment of maternal resources could explain the empirical finding that brain sizes tend to increase in mammals. This general tendency would be promoted by pervasive benefits of increased brain size and specific responses to new behavioral requirements.

However, the long-accepted generalization that mammal brains have typically tended to increase in size over evolutionary time has recently been questioned. With specific reference to bats (order Chiroptera), Safi et al. [2005] proposed that brain size evolution involved reduction rather than enlargement in multiple lineages. The proposal that a decrease in brain size was widespread during bat evolution was explicitly linked to the high energetic cost of maintaining a large brain. However, the inference of widespread brain size reduction was exclusively based on a theoretical analysis of brain size in extant bats.

Safi et al. [2005] did not themselves allocate change in brain size to individual lineages, but they provided the requisite data to Niven [2005], who did so. According to Niven's figure 1, the prevalent trends were for brain size decrease in 7 families (Emballonuridae, Hipposideridae, Molossidae, Noctilionidae, Rhinolophidae, Rhinopomatidae, and Vespertilionidae) and brain size increase in 5 families (Craseonycteridae, Megadermatidae, Mormoopidae, Nycteridae, and Phyllostomidae).

Safi et al. [2005] went on to suggest that in fast-flying bats brain size decreased relative to the ancestral condition because a reduced body mass (BM) was needed to forage in open spaces. According to this proposal, the primary requirement was for flight efficiency. The energetic cost of a large brain was conceivably disadvantageous, so sensory needs were relaxed. By contrast, it was argued that brain size might be expected to increase over time in bats that have large wings for maneuvering in highly structured habitats. Safi et al. [2005] proposed that bats living in such dense habitats would require better spatial memory and hearing for navigation [see also Safi and Dechmann, 2005]. When effects of BM and phylogeny were taken into account by using a phylogenetic leastsquares (PGLS) approach, wing size was found to be positively correlated with brain size in insectivorous bats.
Consideration of fossil specimens is needed to test the claim that reduction in brain size was a widespread occurrence during the evolution of bats, but this is no easy task. Jerison [1973] emphasized the great rarity of fossil bat specimens indicating brain morphology or size, and there appears to be no published record of relative brain size in any species. The absence of published information on brain size in fossil bats is particularly due to their very small body sizes and to the associated rarity of specimens preserved in three dimensions. For instance, the wellknown Eocene bats from Wyoming in the USA (Icaronycteris) and from Messel in Germany (Archaeonycteris, Hassianycteris, Palaeochiropteryx) are documented exclusively by flattened specimens that preclude any direct measurement of brain size. Because prior information on relative brain size in fossil bats was lacking in the literature, collection of new data to meet this need was required. It was necessary to find suitably preserved fossil bat specimens and to apply study methods appropriate to their very small size.

\section{Materials and Methods}

A two-pronged approach was adopted to obtain and interpret fossil evidence to assess direction of change in the evolution of relative brain size in bats: (1) synchrotron radiation X-ray tomographic microscopy (SRXTM) was used to generate virtual endocasts for determination of the brain volume of 6 Oligocene/Miocene bat specimens, and (2) standard dental dimensions were collected for 43 extant microbat species and used to calculate an empirical formula permitting estimation of body size in fossil bats. BM values were taken from Jones et al. [2009].

Higher-level classification of bats (order Chiroptera) requires comment. Traditionally, Chiroptera were divided into two suborders: Microchiroptera (23 families of echolocating microbats) and Megachiroptera (megabats in the single family Pteropodidae). However, reports based on molecular evidence indicated that microchiropterans are polyphyletic, with 5 families (Craseonycteridae, Hipposideridae, Megadermatidae, Rhinolophidae, and Rhinopomatidae) being more closely related to megabats than to the remaining 18 microbat families (Antrozoidae, Craseonycteridae, Emballonuridae, Furipteridae, Hipposideridae, Megadermatidae, Molossidae, Mormoopidae, Mystacinidae, Myzopodidae, Natalidae, Noctilionidae, Nycteridae, Phyllostomidae, Rhinolophidae, Rhinopomatidae, Thyropteridae, and Vespertilionidae). This pattern of relationships has been confirmed by two comprehensive studies of phylogenetic relationships among mammals based on molecular evidence [Bininda-Emonds et al., 2007; Meredith et al., 2011]. A new cladistic classification reflecting these findings allocates Pteropodidae, Craseonycteridae, Hipposideridae, Megadermatidae, Rhinolophidae, and Rhinopomatidae to the suborder Yinpterochiroptera and the remaining 18 microbat families to the suborder Yangochiroptera. To avoid confusion in what follows, the colloquial term 'microbats' will be used for all bats excluding Pteropodidae. 
Table 1. TOMCAT settings used for scanning individual specimens

\begin{tabular}{lllllrr}
\hline Specimen & $\begin{array}{l}\text { Beam } \\
\text { energy, keV }\end{array}$ & $\begin{array}{l}\text { Exposure } \\
\text { time, ms }\end{array}$ & $\begin{array}{l}\text { Projections } \\
\text { over 180 }\end{array}$ & $\begin{array}{l}\text { Step angle } \\
\text { degrees }\end{array}$ & $\begin{array}{l}\text { Magnifi- } \\
\text { cation }\end{array}$ & $\begin{array}{l}\text { Pixel size } \\
\mu m\end{array}$ \\
\hline H. bouziguensis \#1 & 40.005 & 150 & 1,501 & 0.120 & 1 & 7.4 \\
H. bouziguensis \#2 & 40.005 & 150 & 1,501 & 0.120 & 7.4 & 1 \\
H. bouziguensis \#3 & 40.007 & 2,000 & 721 & 0.250 & 1.25 & 7.4 \\
H. schlosseri \#1 & 40.005 & 150 & 1,501 & 0.120 & 1 & 7.4 \\
H. schlosseri \#2 & 40.005 & 150 & 1,501 & 0.120 & 1 & 1.25 \\
H. schlosseri \#3 & 35.004 & 800 & 1,001 & 0.180 & \\
\hline
\end{tabular}

\section{Endocasts of Fossil Bats}

As noted, very few specimens suitable for the study of brain contours are available in collections. However, thanks to a shortterm loan from the Basel Natural History Museum (BNHM), we were able to scan fossils allocated to 2 Hipposideros species. Members of the genus Hipposideros (Old World leaf-nosed bats) are now generally allocated to the family Hipposideridae, although previous classifications sometimes included them as a subfamily in Rhinolophidae. Hipposideridae and Rhinolophidae are both families for which Niven [2005] specifically indicated that brain size reduction could be inferred from the analysis conducted by Safi et al. [2005].

Remains of hipposiderid bats, including a number of relatively complete skulls, are quite common in the Phosphorites de Quercy (Late Eocene-Middle Oligocene of France), actually accounting for the majority of fossil mammal specimens from those deposits. A prominent representative is Hipposideros (Pseudorhinolophus) schlosseri. Dechaseaux [1956] illustrated a natural endocast of this species but provided only linear dimensions; brain volume was not specified. Three relatively complete skulls of $H$. schlosseri were available for scanning in the present study (BNHM specimens QH118, QP787, and QU269). The geological age of the deposits from which the specimens are derived is uncertain, but it is probably close to the Eocene/Oligocene boundary ( $\sim 35 \mathrm{Ma}$ ago). A second species in the same genus and subgenus, Hipposideros (Pseudorhinolophus) bouziguensis is documented in the younger deposits of Bouzigues (France). In fact, this seems to be the last-surviving species of the subgenus Pseudorhinolophus [see Sigé et al., 1997]. The Bouzigues fauna is of Lower Miocene age and attributable to either the first interval (Aquitanian; 23.0-20.4 Ma ago) or the second (Burdigalian; 20.4-16.0 Ma ago). Curiously, many specimens of $H$. bouziguensis - the most abundant mammal species in the Bouzigues fauna - consist predominantly of natural endocasts. This facilitates determination of at least some brain contours even without scans but makes inference of BM problematic as few cranial or dental structures are available for estimation. Edinger [1926] described two natural endocasts of $H$. bouziguensis and Dechaseaux [1938, 1956] portrayed a third. However, for this species, too, only linear measurements were provided. In the present study, three partially exposed natural endocasts of $H$. bouziguensis were subjected to scanning (BNHM specimens G2361a, G2361b, and G2361d).

SRXTM investigations on the 6 fossil bat specimens were performed in March and December 2008 using the TOMCAT beamline [Stampanoni et al., 2006] of the Swiss Light Source at the Paul
Scherrer Institut, Villigen, Switzerland. Scan settings differed between specimens and are listed in table 1. Tomographic reconstructions were computed using a highly optimized routine based on the Fourier transform method [Marone et al., 2010]. The commercial software programs Adobe Photoshop and VGStudio MAX were subsequently used to generate 3-dimensional images of bat endocasts from the tomographic scans.

To provide baseline information and guidance, scans of the skull of an extant bat (Pipistrellus pipistrellus) were acquired and used to generate initial reconstructions of cranial bone and the endocranial cavity (fig. 1). In addition to cranial bone, fossil scans generally included externally attached matrix and/or intrusive matrix that partially or completely filled the cranial cavity. So the program Photoshop (Adobe Systems) was used to clean up each individual image by extracting just the outline of the brain cavity or natural endocast. VGStudio MAX was then used to load all scans together into $3 \mathrm{D}$ volumes and smooth the resulting figures. This program was also used to calculate the volumes of the 6 reconstructed bat endocasts.

Because slice-by-slice extraction of brain contours is a very laborious procedure, specification of reconstruction error is problematic. In order to check on measurement accuracy in the present study without time-consuming repetition of reconstructions, a virtual endocast for one fossil bat specimen was reconstructed independently by two observers. The results obtained were 0.45 and $0.44 \mathrm{~cm}^{3}$, corresponding to a difference of just $2.3 \%$.

\section{Estimation of BM in Fossils}

Standard dental dimensions of the skulls of 43 randomly selected extant bat species were measured with a small sliding caliper. Dental dimensions were exclusively derived from microbats. Wherever possible, average values were determined for 6 skulls for each species, although only 5 skulls were available in a few cases. Dimensions recorded included upper second molar length $\left(M^{2} L\right)$ and width $\left(\mathrm{M}^{2} \mathrm{~W}\right)$, the total length of the upper molars $\left(\mathrm{M}^{1} \mathrm{~L}+\mathrm{M}^{2} \mathrm{~L}\right.$ $+\mathrm{M}^{3} \mathrm{~L}$ ), and the distance between right and left upper second molars. Molar dimensions have been widely used as predictors for BM in a broad spectrum of mammals. BM values were taken from the PanTHERIA compilation of Jones et al. [2009]. In the fossils, linear measurements were taken directly from $H$. schlosseri. However, since only the natural endocasts were available for H. bouziguensis, it was necessary to use the average linear values cited by Sigé [1968] for remains of $H$. bouziguensis from Bouzigues.

Steps were taken to allow for the possible influence of phylogenetic inertia in quantitative comparisons. To determine an em- 


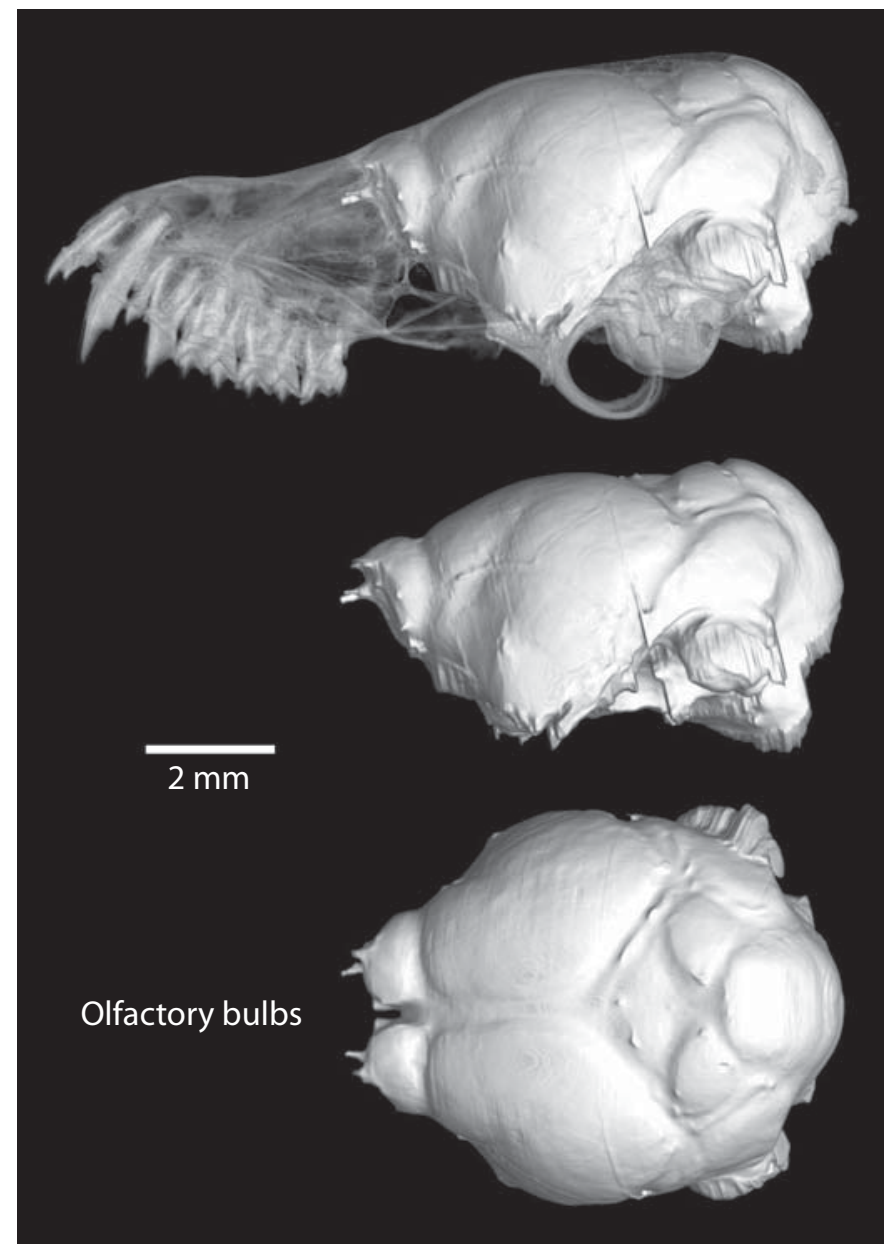

Fig. 1. Reconstructed skull and 3 views of a virtual endocast of the extant bat $P$. pipistrellus (common pipistrelle). Like many other microchiropteran bats, the common pipistrelle is very small, with a skull length of only $12.2 \mathrm{~mm}$. High-resolution SRXTM is therefore needed for clear visualization. The endocast volume of this specimen is $110 \mathrm{~mm}^{3}$, which agrees closely with an average brain mass of $95 \pm 10 \mathrm{mg}$ reported for $P$. pipistrellus [Djavadian et al., 2006].

pirical formula for estimating body size in fossil bats, a phylogenetic tree was constructed by combining the mammal supertree of Bininda-Emonds et al. [2007] with a tree based on cytochrome $b$ genes provided by Agnarsson et al. [2011]. The better resolved Agnarsson tree was used as a starting point, and 10 species were added from the Bininda-Emonds tree. Branch lengths were adjusted in order to yield an ultrametric tree, i.e. one in which all species exhibit the same distance from the root of the tree. To estimate body size from dental dimensions, a PGLS approach using the package Comparative Analyses of Phylogenetics and Evolution in R (caper) [Orme et al., 2011; R Development Core Team, 2011] was applied. The best model was selected according to the Akaike information criterion (AIC).

\section{Estimating Relative Brain Size}

Having inferred BM for the two fossil bat species, we calculated their relative brain sizes using extant bats as the point of reference. A tree for extant bat species was derived from Agnarsson et al. [2011], including only species for which both brain and BM data are available (from Baron et al. [1996] and Jones and MacLarnon [2004], after excluding questionable data). Branch lengths were transformed to chronologic equivalents using the BEAST package (v1.6.2, Drummond and Rambaut [2007]). As in the residuals first method of Montgomery et al. [2010], residuals of brain versus BM were calculated relative to a phylogenetically controlled empirical regression slope of 0.682 .

\section{Directionality of Evolutionary Trends}

In order to investigate whether inclusion of the two fossil species influences the estimates of ancestral states, or recognition of a directional trend in the evolution of relative brain size, we used BayesTraits 1.1 [Pagel, 1999; Pagel et al., 2004, including the former package CONTINUOUS]. We tested between a constantvariance random walk model and a directional random walk model, using both a maximum parsimony (MP) and a Bayesian Markov Chain Monte Carlo (MCMC) approach. For MP, a likelihood test was performed to choose between these two models, and for MCMC, the harmonic means of the log-likelihoods of all models visited by the chain were compared by examining the BayesFactor. The testing procedures are described in detail by Montgomery et al. [2010], who conducted an analogous analysis in primates. However, to assess a directional trend in the evolution of a trait, the tree reflecting the phylogenetic relationships must show some variation in the root-to-tip lengths, i.e. the tree must not be ultrametric [Pagel, 1997, 1999; Organ et al., 2007]. Therefore, such a test can only be performed in a tree that includes fossil species.

As shown in figure 2, the two fossil species, H. schlosseri and $H$. bouziguensis, were inserted into the tree in a position basal to the node giving rise to all extant Hipposideros species together with Asellia/Aselliscus/Coelops. This position was constrained by the age of the fossils, which predates the ancestral node for Hipposideros/Asellia/Aselliscus/Coelops species but postdates the time of divergence between that clade and Triaenops.

Because both fossil species examined are most probably related to extant Hipposideridae, Megadermatidae, and Rhinolophidae, all tests were performed both for a reduced tree including only those 3 families ( $\mathrm{n}=34$ species) and for an overall tree for Chiroptera ( $\mathrm{n}=199$ species).

\section{Reconstructing Ancestral States}

We applied two different methods to estimate the relative brain size of the most recent common ancestor of several clades: MP in Mesquite (weighted squared-change parsimony [Maddison and Maddison, 2011]) and the Bayesian MCMC approach in BayesTraits 1.1 [Pagel, 1999; Pagel et al., 2004]. For the latter, the parameters of the model are estimated first, and in a second step the ancestral states for that model are calculated as the average of all posterior distribution values, excluding the first 500,000 values from the burn-in period. Ancestral states were estimated for trees both with fossils ( $\mathrm{n}=199$ species) and without fossils $(\mathrm{n}=$ 197 species). 


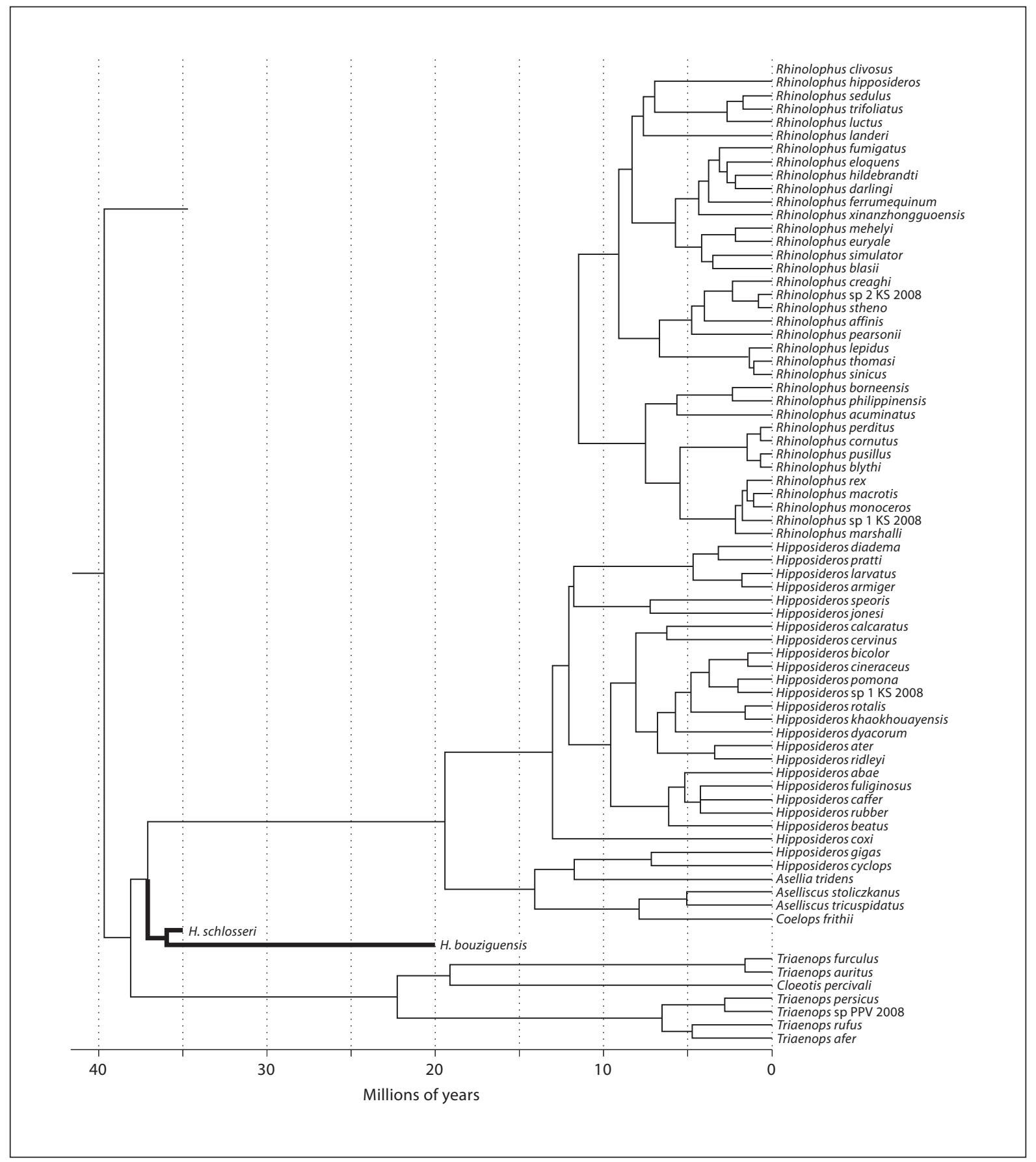

Fig. 2. Inferred phylogenetic tree for extant Rhinolophidae and Hipposideridae, including the two fossil species $H$. (Pseudorhinolophus) schlosseri and H. (Pseudorhinolophus) bouziguensis, with lineages indicated by heavy lines (this is an extract from an overall phylogenetic tree for bats based on Bininda-Emonds et al. [2007] and Agnarsson et al. [2011]). Because the two fossil species are probably sister taxa and because their common ancestor would have existed $\geq 35 \mathrm{Ma}$ ago, their lineage must have diverged at least $15 \mathrm{Ma}$ prior to the node that gave rise to extant Hipposideros, Asellia, Aselliscus, and Coelops but after divergence of the lineage leading to Triaenops species. 


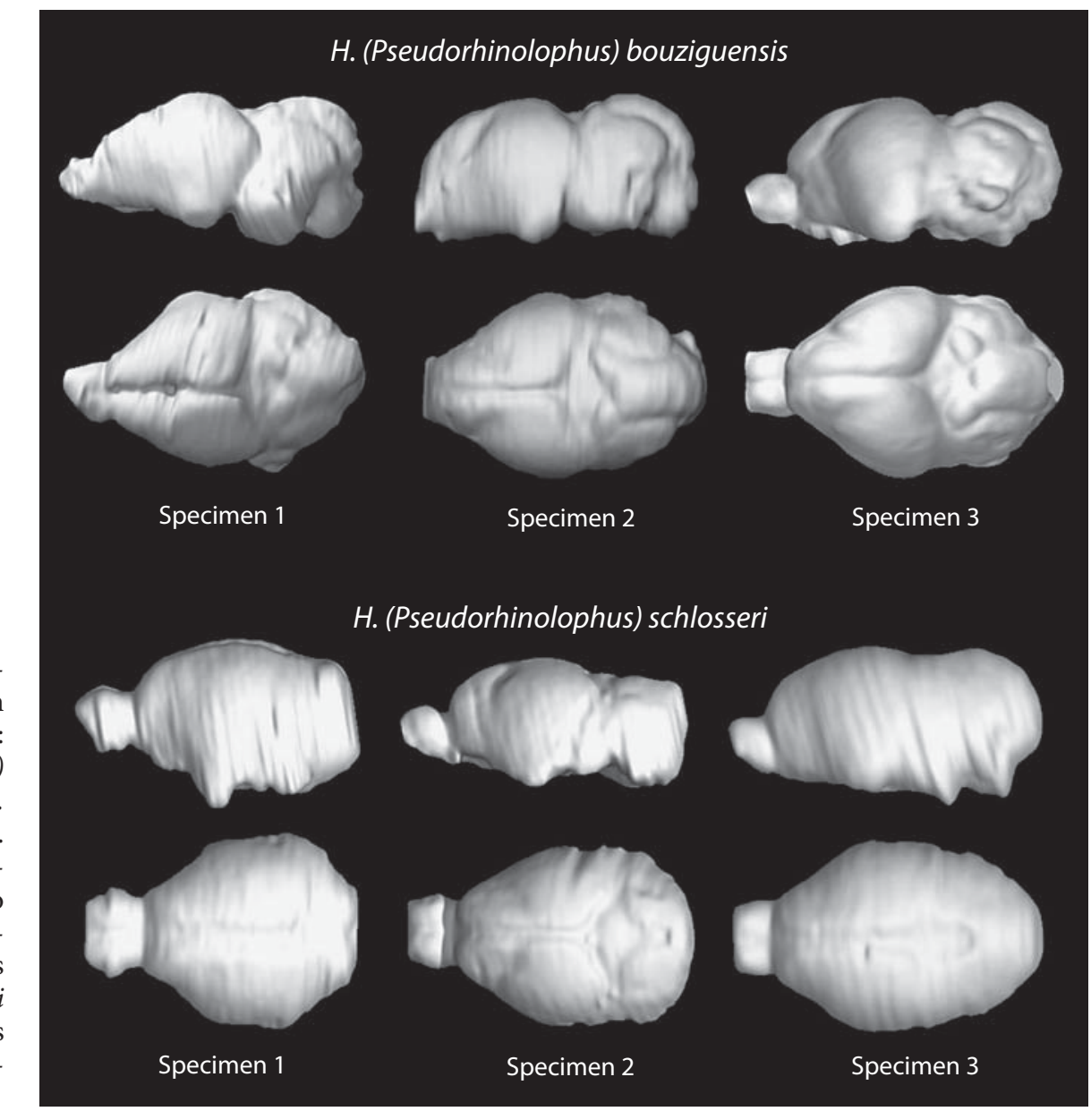

Fig. 3. Smoothed virtual endocasts reconstructed from 6 fossil bat specimens from 2 species of the family Hipposideridae: early Oligocene $H$. (Pseudorhinolophus) schlosseri $(\mathrm{n}=3)$ and early Miocene $H$. (Pseudorhinolophus) bouziguensis $(\mathrm{n}=3)$. In the specimens of $H$. bouziguensis, natural endocasts were already exposed to varying degrees, so extraction only required removal of various skull fragments and attached matrix. Skulls of $H$. schlosseri were more complete, so their endocasts had to be reconstructed from internal profiles of the braincase.

Fig. 4. Bivariate logarithmic plot of brain mass (g) against BM (g) for all available extant bat species (filled circles) and the two fossil species (open squares). Data for the brain and BM of extant bats were taken from Jones et al. [2009]. As explained in the text, the BM of the fossils was estimated from upper second molar dimensions. Best-fit lines shown are a least-squares regression fitted to the raw data (thin line) and a phylogenetically corrected line (PGLS; thick line). Both fossil species fall into the lower region of the distribution for extant bats.

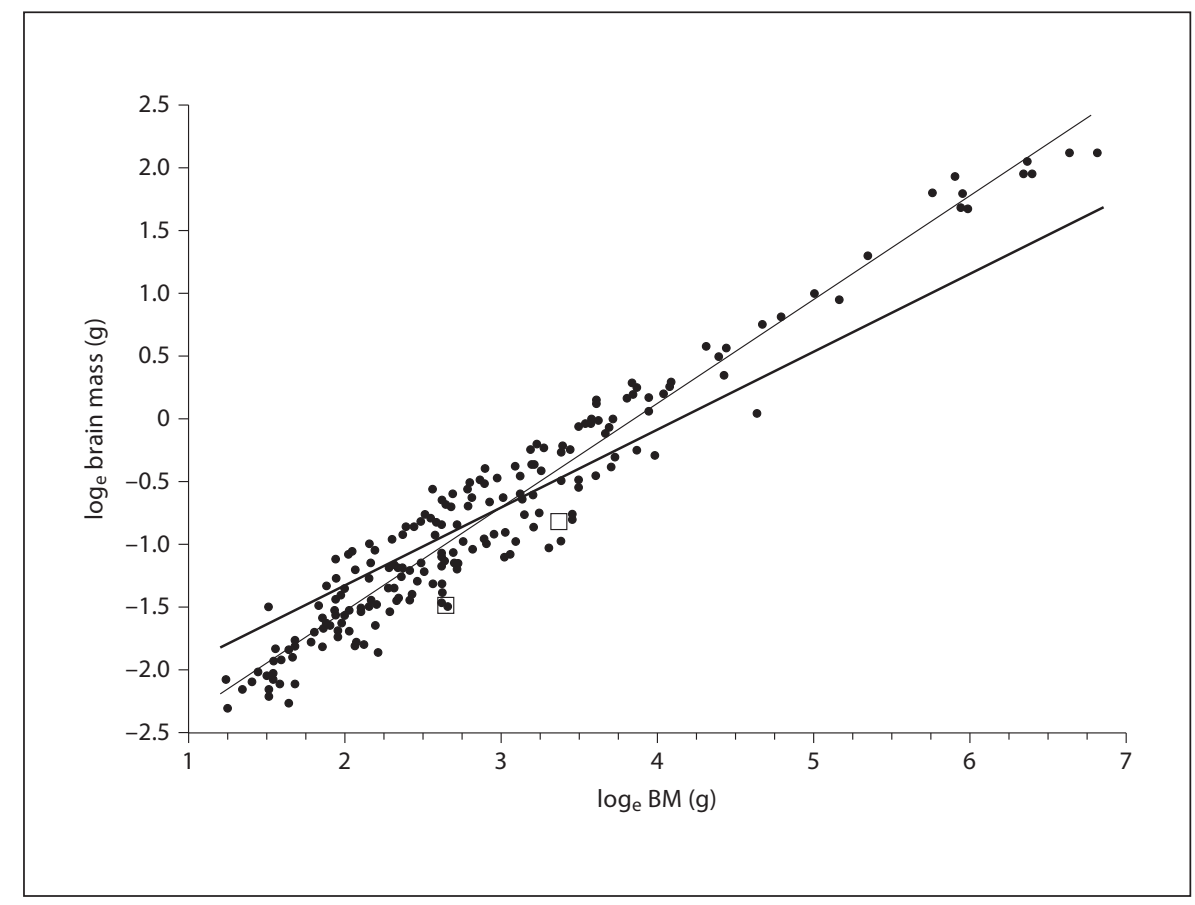




\section{Results}

\section{Fossil Endocast Volume}

Three-dimensional virtual endocasts were successfully reconstructed for all 6 fossil bat specimens scanned at TOMCAT (fig. 3). The following endocast volumes were determined: (1) H. schlosseri - specimen $1=0.24 \mathrm{~cm}^{3}$, specimen $2=0.19 \mathrm{~cm}^{3}$, specimen $3=0.27 \mathrm{~cm}^{3}$, and (2) $H$. bouziguensis - specimen $1=0.46 \mathrm{~cm}^{3}$, specimen $2=0.44$ $\mathrm{cm}^{3}$, specimen $3=0.45 \mathrm{~cm}^{3}$.

\section{Fossil BM Estimates}

Possibilities for estimation of BM were limited because all fossil bat specimens studied were fragmentary. $M^{2} L$ and $\mathrm{M}^{2} \mathrm{~W}$ could be measured for all three specimens of $H$. schlosseri. However, all three specimens of $H$. bouziguensis lacked teeth, so average values for $\mathrm{M}^{2} \mathrm{~L}$ and $\mathrm{M}^{2} \mathrm{~W}$ were taken from a monographic account of remains from Bouzigues by Sigé [1968]. Analysis using PGLS indicated that a combination of $\mathrm{M}^{2} \mathrm{~L}$ and $\mathrm{M}^{2} \mathrm{~W}$ yielded better predictive power than either measurement alone (see Appendix for phylogenetic models and data). The following phylogenetically corrected allometric formula relating $\mathrm{BM}$ (in g) to $\mathrm{M}^{2} \mathrm{~L}$ and $\mathrm{M}^{2} \mathrm{~W}$ (both in $\mathrm{mm}$ ) was derived:

$\log _{e} B M=1.4897 \times \log _{e} M^{2} L+0.9096 \times \log _{e} M^{2} W+1.4853$

This formula yielded an average BM of $14.0 \mathrm{~g}$ for $H$. schlosseri and an average of $28.7 \mathrm{~g}$ for $\mathrm{H}$. bouziguensis.

\section{Analysis of Relative Brain Size}

When included in a bivariate logarithmic plot of brain size against BM for extant bats, values for the fossils (brain size from endocasts; body size estimated from upper second molar dimensions) fall into the lower region of the distribution (fig. 4). This is evident both relative to a least-squares regression fitted to the raw data and relative to a phylogenetically controlled line determined with PGLS. It is also noteworthy that relative brain size in the earlier, smaller-bodied fossil (Oligocene H. schlosseri) is somewhat lower than in the more recent, largerbodied fossil (Miocene H. bouziguensis), as would be expected if relative brain size tends to increase over time.

Phylogenetic analysis with both MP and Bayesian MCMC revealed that a directional model of evolution was more likely for relative brain size although this is not true either for brain size or for body size taken in isolation. In other words, a positive trend of relative brain size through the evolutionary history of bats fits the data better than a random walk model (table 2). The same result emerged regardless of whether the analysis was conduct-

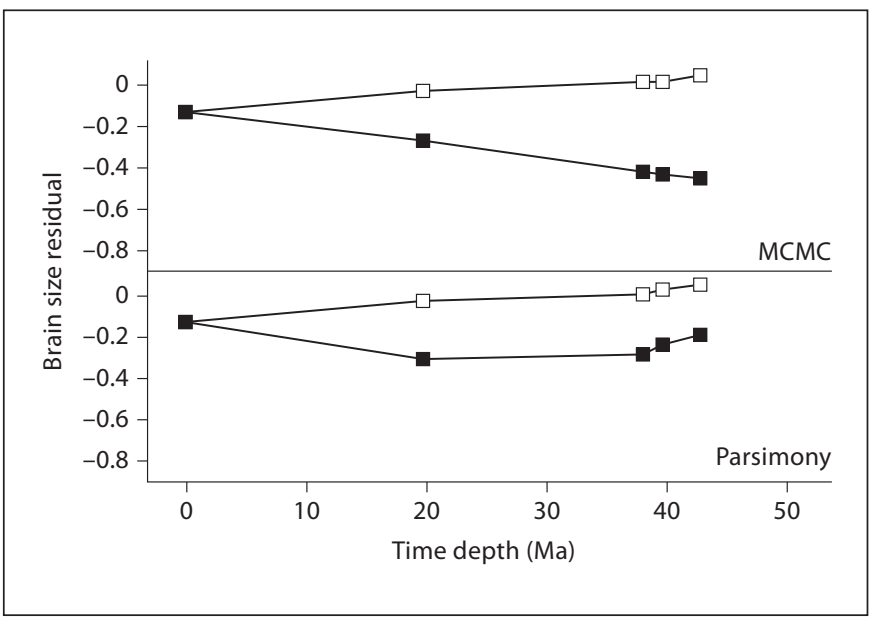

Fig. 5. Ancestral state estimations for relative brain size (logarithmic residual value) with fossils (filled squares) and without (open squares). Inclusion of the fossils consistently lowers the value for relative brain size inferred for ancestral nodes, both with MP and with MCMC.

ed with the entire combined tree of Chiroptera ( $n=197$ extant species) or with a reduced tree including only the 3 families Hipposideridae, Megadermatidae, and Rhinolophidae ( $\mathrm{n}=32$ species). The result is highly significant with MP ( $p<0.0001$ and $\mathrm{p}=0.0001$, respectively). With Bayesian MCMC, a BayesFactor value $>2$ indicates a convincing result, so the high values obtained with all bats or with just the 3 families indicated (13.10 and 12.64, respectively) provide strong support for directional evolution of relative brain size.

Ancestral state estimations using MP and Bayesian MCMC (table 3) further indicate that the inclusion of fossils yields considerably lower ancestral values for nodes close in age to the fossil species (fig. 5). With deeper nodes, however, the fossils have less influence on parsimony estimates, and values approach those estimated without fossils. Bayesian MCMC, on the other hand, yields consistently low estimates of relative brain size for the deepest nodes when fossils are included. Overall, it seems likely that the relative brain size of the common ancestor of all bats was relatively small.

\section{Discussion}

The results of this first study of relative brain size in fossil bats provide no indication that any decrease has occurred in the genus Hipposideros over the past $35 \mathrm{Ma}$. 
Table 2. Results of tests for evolutionary trends in BM, brain size, and relative brain size

\begin{tabular}{|c|c|c|c|c|c|}
\hline Variable & $\begin{array}{l}\text { likelihood } \\
\text { ratio }\end{array}$ & $\mathrm{p}$ value & $\begin{array}{l}\text { HMLL random } \\
\text { walk model }\end{array}$ & $\begin{array}{l}\text { HMLL } \\
\text { directional model }\end{array}$ & BayesFactor \\
\hline \multicolumn{6}{|c|}{ In all Chiroptera sampled ( $\mathrm{n}=199$ species) } \\
\hline $\mathrm{BM}$ & 0.036 & 0.850 & -219.88 & -220.47 & -1.18 \\
\hline Brain size & 1.678 & 0.195 & -152.55 & -152.88 & -0.66 \\
\hline $\mathrm{BM}$ & 0.028 & 0.867 & -31.42 & -32.44 & -2.04 \\
\hline Brain size & 1.492 & 0.222 & -20.59 & -20.79 & -0.40 \\
\hline Relative brain size & 14.454 & 0.0001 & 19.67 & 25.99 & 12.64 \\
\hline
\end{tabular}

HMLL = Harmonic mean of log-likelihood.

Table 3. Estimates of ancestral values of relative brain size for all bats, with fossils ( $\mathrm{n}=199$ species; before slash) or without $(\mathrm{n}=197$ species; after slash)

\begin{tabular}{llc}
\hline & Parsimony & Bayesian MCMC \\
\hline Node 181: Hipposideros & $-0.128 /-0.110$ & $-0.210 /-0.089$ \\
Node 147: Rhinolophus & $-0.133 /-0.113$ & $-0.255 /-0.067$ \\
Node 179: Hipposideros and Asellia/Aselliscus/Coelops & $-0.402 /-0.136$ & $-0.301 /-0.169$ \\
Node 178: Hipposideridae & $-0.362 /-0.076$ & $-0.518 /-0.088$ \\
Node 146: Rhinolophidae and Hipposideridae & $-0.298 /-0.059$ & $-0.525 / 0.001$ \\
Node 142: Megadermatidae, Rhinolophidae, and Hipposideridae & $-0.193 /-0.020$ & $-0.599 /-0.017$ \\
Node 141: Yinpterochiroptera & $-0.127 /-0.003$ & $-0.533 /-0.052$ \\
Node 3: Yinpterochiroptera and part of Yangochiroptera & $-0.136 /-0.053$ & $-0.668 /-0.097$ \\
Node 2: all Chiroptera & $-0.170 /-0.113$ & $-0.847 /-0.112$ \\
\hline
\end{tabular}

This conflicts with the conclusion drawn by Safi et al. [2005] that evolutionary decrease in brain size has been widespread among bats, notably including members of the family Hipposideridae [Niven, 2005]. The findings for fossil Hipposideros are, instead, compatible with the interpretation that relative brain size has generally increased over time during mammalian evolution, albeit at different stages and at different rates. In fact, phylogenetic analyses conducted with or without our data for relative brain size in two Hipposideros species provide statistically significant evidence for a general trend towards increased relative brain size during the evolution of bats.

In some mammalian lineages, notably in insectivores (both afrosoricidan and eulipotyphlan), expansion in brain size has been very limited. By contrast, in certain other lineages - especially in toothed cetaceans, canid carnivores, and hominids - major expansions of relative brain size have taken place. A recent review by Shultz and Dunbar [2010], which explicitly included fossil evidence, confirmed the overall picture for mammals, ranging from very little change in some lineages to marked change in others. But their findings provided no indication that relative brain size has actually decreased in any lineage.

Relative brain size in certain extant insectivores characterized as 'basal' (members of the families Erinaceidae and Soricidae) has often been taken as representative of the ancestral condition for placental mammals. However, while it is true that these insectivores generally have very small brains in comparison with other extant mammals, they are by no means unique in this regard. Many rodents, for example, have relative brain sizes lying within the 'basal' insectivore range. Moreover, few attempts have 
been made to reconstruct the ancestral condition using actual fossil evidence. Ancestral placentals emerged at least $125 \mathrm{Ma}$ ago and perhaps as far back as >160 Ma ago [Luo et al., 2011], and we need to infer relative brain size at the outset in order to trace the evolutionary history of encephalization among placental mammals with any confidence. The oldest fossil mammals included in the analysis conducted by Shultz and Dunbar [2010] date back to only $\sim 60 \mathrm{Ma}$ ago, leaving up to $100 \mathrm{Ma}$ of prior evolutionary history completely undocumented. Limited evidence for relative brain size in Cretaceous mammals (>65 Ma old) indicated that relative brain size was even smaller than in most or all extant insectivores [Martin and Isler, 2010], and this has now been confirmed by an analysis of improved evidence [Rowe et al., 2011]. Nonetheless, 'basal' insectivores, various rodents, and certain other mammals do provide a lower bound for relative brain size among mammals alive today.

As far as bats are concerned, it was established some time ago that frugivorous bats as a group have markedly larger brains, relative to body size, than insectivorous bats [Eisenberg and Wilson, 1978]. In fact, most values for relative brain size in frugivorous bats lie above the average for extant placental mammals, while the vast majority of values for insectivorous bats lie below that average level. Indeed, some microbats have relative brain sizes lying in the lower region of the distribution for extant placental mammals. Therefore, insectivorous microbats count among notably small-brained mammals. This can be explained in one of two ways. One possibility, raised by the claim made by Safi et al. [2005], is that extant insectivorous bats commonly have small brains because of widespread reduction from a larger-brained ancestry. However, the alternative possibility is that insectivorous bats have always been relatively small-brained and that comparatively little expansion occurred from the ancestral placental condition. If no convincing case can be made for a reduction in brain size among bats, then the straightforward interpretation is that there was little scope for any such reduction from the ancestral chiropteran condition; their brains simply failed to expand to any marked degree. This is the interpretation supported by the findings presented here.

In contrast to our results, Safi et al. [2005], using the same procedures, found no evidence for a directional trend in relative brain size evolution in bats. However, at the time there were no fossil data available, and in the phylogenetic tree all branches between bifurcations had been assigned equal length. As a result, species in speciesrich groups in their tree necessarily exhibit a longer path- way from root to tip than species in groups containing relatively few species. The directionality parameter in BayesTraits measures the regression of trait values across species against the total path length from the root of the tree to the tips. Thus, Safi et al. [2005] actually tested whether species-rich groups differ in relative brain size from less speciose groups and did not find any indication that this was the case.

It is in any case questionable whether change in a morphological character over time can be reliably inferred in the absence of fossil evidence. Analysis of body size in the mammalian order Carnivora by Finarelli and Flynn [2006] clearly illustrates potential pitfalls in reconstructing changes in size over time with exclusive reference to extant species. Among caniform carnivorans (Canidae, Ursidae, Pinnipedia, Musteloidea), many subgroups are now represented predominantly by large- or small-bodied species. The distribution of body sizes among extant species across the phylogeny seemingly indicates a pattern of decreasing body size from an ancestral value of 10-50 kg. However, body sizes estimated for fossil representatives of a given caniform taxon often lie well outside the observed ranges for extant members. Therefore, the present-day distribution of body sizes is not representative of the evolutionary history of the group. When 367 fossil taxa were included with 149 extant species in a combined analysis designed to reconstruct ancestral body sizes, a small-bodied ancestor $(1-5 \mathrm{~kg})$ was indicated both for Caniformia and for the monophyletic subclade Arctoidea (Ursidae, Pinnipedia, Musteloidea). As Finarelli and Flynn [2006] noted, 'Evolutionary trends can reduce the accuracy of character state reconstructions, especially for methods assuming Brownian motion as the model for character change. This is because an estimated root value under such a model will always be some form of weighted average of observed values for terminal taxa [Schluter et al., 1997], and if a trend moves the range of observed character state values beyond the ancestral condition, it will be difficult, if not impossible, to accurately reconstruct the condition at the ancestral node [Garland et al., 1999; Oakley and Cunningham, 2000]'. At present, the most promising method is based on an adaptive peak model of evolution [Smaers and Vinicius, 2009], which is, however, not yet available as a software package.

The topic of brain size reduction has attracted considerable interest since 2004 because of the discovery of fossil hominid remains attributed to the putative new species Homo floresiensis [Brown et al., 2004]. One remarkable feature of the primary Flores hominid specimen LB1 is its tiny brain size, which is quite unusual for a hominid 
that is only 18,000 years old. Various attempts have been made to explain the small brain of LB1 as a result of island dwarfism [Niven, 2007], or by referring to brain size reduction in other lineages [Dechmann and Safi, 2009; Montgomery et al., 2010]. However, several research groups have proposed instead that the LB1 individual was in fact a modern human suffering from a pathological condition [Weber et al., 2005; Martin et al., 2006a, b; 2008; Vannucci et al., 2011]. Our results demonstrate that including fossils in a reconstruction strongly supports a positive directionality in the relative size of bat brains over time. Therefore, bats cannot be used as an argument to assign species status to LB1.

\section{Acknowledgments}

We owe special thanks to Dr. Burkart Engesser, Emeritus Conservator for Geological Sciences at the Natural History Museum in Basel (Switzerland), for helping to select suitable fossil bat specimens for SRXTM and for arranging a short-term loan of those specimens. Dr. Engesser also arranged the loan of a skull of $P$. pipistrellus. We are also very grateful to William Stanley (Negaunee Collection Manager) and Dr. Lawrence Heaney (Curator and Head) of the Mammals Section in the Zoology Department of The Field Museum for providing helpful advice and access to specimens of extant bats for measurement. Lu Yao was supported by an Undergraduate Research Grant from Northwestern University (Chicago, Ill., USA) in the summer of 2009 to generate $3 \mathrm{D}$ reconstructions of virtual endocasts from SRXTM datasets and to conduct measurements on skulls of extant bat species. Brooke Parker generated a 3D reconstruction for one of the 6 virtual endocasts while working as a summer intern in 2008. Thanks go to Michel Genoud for providing valuable comments on a draft of this paper. We gratefully acknowledge funding and operational support from the Swiss Light Source to conduct this study. Richards, 2006; Hershkovitz et al., 2007; Obendorf et al.,

\begin{tabular}{|c|c|c|c|c|}
\hline Species & $\begin{array}{l}\mathrm{M}^{2} \mathrm{~L} \\
\mathrm{~mm}\end{array}$ & $\begin{array}{l}\mathrm{M}^{2} \mathrm{~W} \\
\mathrm{~mm}\end{array}$ & $\begin{array}{l}\text { M1 to } \\
\text { M3, mm }\end{array}$ & $\begin{array}{l}\text { M2 to } \\
\text { M2, mm }\end{array}$ \\
\hline Leptonycteris curasoae & 2.1 & 0.9 & 5.0 & 6.5 \\
\hline Megaderma lyra & 2.8 & 2.7 & 6.2 & 9.5 \\
\hline Molossus molossus & 1.8 & 2.1 & 4.1 & 7.5 \\
\hline Molossus rufus & 2.2 & 2.5 & 5.0 & 9.0 \\
\hline Molossus sinaloae & 2.2 & 2.3 & 5.0 & 9.1 \\
\hline Mops condylurus & 2.3 & 2.1 & 4.9 & 8.7 \\
\hline Murina tubinaris & 1.3 & 1.3 & 2.8 & 5.1 \\
\hline Myotis adversus & 1.4 & 1.4 & 3.1 & 6.0 \\
\hline Myotis albescens & 1.3 & 1.2 & 2.9 & 5.3 \\
\hline Noctilio leporinus & 3.0 & 2.9 & 7.1 & 12.0 \\
\hline Otomops martiensseni & 2.4 & 2.1 & 6.0 & 9.8 \\
\hline Phyllostomus elongatus & 2.7 & 2.8 & 6.1 & 10.4 \\
\hline Phyllostomus hastatus & 2.7 & 3.4 & 6.9 & 13.1 \\
\hline Pipistrellus kuhlii & 1.3 & 1.4 & 2.9 & 5.6 \\
\hline Platyrrhinus infuscus & 2.9 & 2.7 & 6.0 & 11.3 \\
\hline Rhinolophus acuminatus & 1.9 & 1.9 & 5.0 & 7.8 \\
\hline Rhinolophus ferrumequinum & 2.1 & 1.9 & 5.1 & 7.9 \\
\hline Rhinolophus luctus & 2.7 & 2.4 & 6.8 & 10.4 \\
\hline Rhinolophus thomasi & 1.5 & 1.3 & 3.7 & 5.7 \\
\hline Rhogeesa tumida & 1.3 & 1.1 & 2.6 & 4.8 \\
\hline Saccopteryx canescens & 1.2 & 1.1 & 2.8 & 5.4 \\
\hline Scotomanes ornatus & 2.4 & 2.3 & 4.6 & 8.6 \\
\hline Scotophilus heathi & 2.1 & 2.6 & 4.6 & 9.5 \\
\hline Sphaeronycteris taxophyllum & 1.2 & 1.7 & 2.7 & 7.3 \\
\hline Sturnira ludovici & 1.1 & 1.4 & 3.4 & 8.0 \\
\hline Taphozous hildegardeae & 2.0 & 2.0 & 4.6 & 8.6 \\
\hline Taphozous mauritianus & 2.2 & 2.2 & 4.8 & 8.5 \\
\hline Taphozous melanopogon & 2.0 & 2.1 & 4.7 & 8.5 \\
\hline Thyroptera tricolor & 1.3 & 1.1 & 2.9 & 4.9 \\
\hline Triaenops persicus & 1.7 & 1.4 & 3.9 & 6.2 \\
\hline Vampyrodes caraccioli & 2.7 & 2.8 & 5.1 & 12.2 \\
\hline Vampyrum spectrum & 4.4 & 4.3 & 9.9 & 14.6 \\
\hline
\end{tabular}

\section{References}

\section{Appendix}

\begin{tabular}{llllc}
\hline Species & $\begin{array}{l}\mathrm{M}^{2} \mathrm{~L} \\
\mathrm{~mm}\end{array}$ & $\begin{array}{l}\mathrm{M}^{2} \mathrm{~W} \\
\mathrm{~mm}\end{array}$ & $\begin{array}{l}\mathrm{M} 1 \text { to } \\
\mathrm{M} 3, \mathrm{~mm}\end{array}$ & $\begin{array}{l}\mathrm{M} 2 \text { to } \\
\mathrm{M} 2, \mathrm{~mm}\end{array}$ \\
\hline Anoura geoffroyi & 1.5 & 0.9 & 3.8 & 5.6 \\
Artibeus jamaicensis & 2.1 & 3.0 & 4.4 & 11.9 \\
Carollia perpicillata & 1.6 & 1.6 & 3.7 & 7.5 \\
Chaerephon pumilus & 1.5 & 1.5 & 3.6 & 6.5 \\
Cormura brevirostris & 1.8 & 1.8 & 3.6 & 7.0 \\
Hipposideros armiger & 3.1 & 2.9 & 7.3 & 11.8 \\
Hipposideros commersoni & 2.7 & 2.6 & 6.4 & 11.2 \\
Hipposideros diadema & 2.9 & 2.7 & 6.8 & 11.0 \\
Hipposideros lankadiva & 3.1 & 3.1 & 7.6 & 12.1 \\
Hipposideros ruber & 1.6 & 1.4 & 3.8 & 6.4 \\
Ia io & 3.0 & 3.0 & 6.7 & 10.5 \\
\hline
\end{tabular}

-Agnarsson I, Zambrana-Torrelio CM, FloresSaldana NP, May-Collado LJ (2011): A timecalibrated species-level phylogeny of bats (Chiroptera, Mammalia). PLoS Curr 3:1-34.

Armstrong E (1983): Relative brain size and metabolism in mammals. Science 220:13021304.

Baron G, Stephan H, Frahm HD (1996): Comparative Neurobiology in Chiroptera. Basel, Birkhäuser.

- Bininda-Emonds OR, Cardillo M, Jones KE, MacPhee RD, Beck RM, Grenyer R, Price SA, Vos RA, Gittleman JL, Purvis A (2007): The delayed rise of present-day mammals. Nature 446:507-512.

Brown P, Sutikna T, Morwood MJ, Soejono RP, Saptomo EW, Due RA (2004): A new smallbodied hominin from the Late Pleistocene of Flores, Indonesia. Nature 431:1055-1061.

Dechaseaux C (1938): L'encéphale d'un chiroptère fossile. Bull Soc Géol Fr 18:105-109.

Yao/Brown/Stampanoni/Marone/Isler/ Martin 
Dechaseaux C (1956): Moulages endocraniens naturels des chiroptères fossiles. Ann Paléontol 42:119-137.

Dechmann DK, Safi K (2009): Comparative studies of brain evolution: a critical insight from the Chiroptera. Biol Rev Camb Philos Soc 84:161-172.

Djavadian R, Ghazaryan A, Yavrouyan EG Turlejski K (2006): Generation of brain cells in adult microbats. FENS Abstr 3:A086.8.

Drummond AJ, Rambaut A (2007): BEAST: Bayesian evolutionary analysis by sampling trees. BMC Evol Biol 7:214.

Edinger T (1926): Fossile Fledermausgehirne. Senckenbergiana 8:1-6.

-Eisenberg JF, Wilson DE (1978): Relative brain size and feeding strategies in the Chiroptera. Evolution 32:740-751.

-Finarelli JA, Flynn JJ (2006): Ancestral state reconstruction of body size in the Caniformia (Carnivora, Mammalia): the effects of incorporating data from the fossil record. Syst Biol 55:301-313.

Finarelli JA, Flynn JJ (2007): The evolution of encephalization in caniform carnivorans. Evolution 61:1758-1772.

Garland T, Midford PE, Ives AR (1999): An introduction to phylogenetically based statistical methods, with a new method for confidence intervals on ancestral values. Am Zool 39:374-388.

Hershkovitz I, Kornreich L, Laron Z (2007): Comparative skeletal features between $\mathrm{Ho}$ mo floresiensis and patients with primary growth hormone insensitivity (Laron Syndrome). Am J Phys Anthropol 134:198-208.

Jerison HJ (1973): Evolution of the Brain and Intelligence. New York, Academic Press.

- Jones KE, Bielby J, Cardillo M, Fritz SA, O’Dell J, Orme CD, Safi K, Sechrest W, Boakes EH, Carbone C, Conolly C, Cutts MC, Foster JK, Grenyer R, Habib M, Plaster CA, Price SA, Rigby EA, Rist J, Teacher A, Bininda-Emonds OR, Gittleman JL, Mace GM, Purvis A (2009): PanTHERIA: a species-level database of life history, ecology, and geography of extant and recently extinct mammals. Ecology 90:2648.

-Jones KE, MacLarnon AM (2004): Affording larger brains: testing hypotheses of mammalian brain evolution on bats. Am Nat 164:E20-E31

Luo ZX, Yuan CX, Meng QJ, Ji Q (2011): A Jurassic eutherian mammal and divergence of marsupials and placentals. Nature 476:442-445.

Maddison WP, Maddison DR (2011): Mesquite: a modular system for evolutionary analysis - version 2.75. http://mesquiteproject.org.

Marino L, McShea DW, Uhen MD (2004): Origin and evolution of large brains in toothed whales. Anat Rec 281A:1247-1255.

Marone F, Munch B, Stampanoni M (2010): Fast reconstruction algorithm dealing with tomography artifacts; in Stock SR (ed): Developments in X-Ray Tomography VII, vol 7804. Proceedings of SPIE - The International Society for Optical Engineering.
Marsh OC (1874): Small size of the brain in Tertiary mammals. Am J Sci Arts 8:66-67.

Martin RD (1981): Relative brain size and metabolic rate in terrestrial vertebrates. Nature 293:57-60.

Martin RD (1990): Primate Origins and Evolution: A Phylogenetic Reconstruction. New Jersey, Princeton University Press.

Martin RD (1996): Scaling of the mammalian brain: the maternal energy hypothesis. News Physiol Sci 11:149-156.

Martin RD, Isler K (2010): The maternal energy hypothesis of brain evolution: an update; in Broadfield D, Yuan M, Toth N, Schick K (eds): The Human Brain Evolving: Papers in Honor of Ralph L. Holloway. Bloomington, Stone Age Institute Press, pp 15-35.

- Martin RD, MacLarnon AM, Phillips JL, Dobyns WB (2006a): Flores hominid: new species or microcephalic dwarf? Anat Rec 288A:11231145.

- Martin RD, MacLarnon AM, Phillips JL, Dussubieux L, Williams PR, Dobyns WB (2006b): Comment on 'The brain of LB1, Homo floresiensis' (technical comment). Science 312:999b.

- Meredith RW, Janečka JE, Gatesy J, Ryder OA, Fisher CA, Teeling EC, Goodbla A, Eizirik E, Simão TLL, Stadler T, Rabosky DL, Honeycutt RL, Flynn JJ, Ingram, CM, Steiner C, Williams TL, Robinson TJ, Burk-Herrick A, Westerman M, Ayoub NA, Springer MS, Murphy WJ (2011): Impacts of the Cretaceous terrestrial revolution and KPg extinction on mammal diversification. Science 334:521-524.

- Mink JW, Blumenshine RJ, Adams DB (1981): Ratio of central nervous system to body metabolism in vertebrates: its constancy and functional basis. Am J Physiol 241:R203R212.

Montgomery SH, Capellini I, Barton RA, Mundy NI (2010): Reconstructing the ups and downs of primate brain evolution: implications for adaptive hypotheses and Homo floresiensis. BMC Biol 8:9.

Niven JE (2005): Brain evolution: getting better all the time? Curr Biol 15:R624-R626.

-Niven JE (2007): Brains, islands and evolution: breaking all the rules. Trends Ecol Evol 22: 57-59.

Oakley TH, Cunningham CW (2000): Independent contrasts succeed where ancestor reconstruction fails in a known bacteriophage phylogeny. Evolution 54:397-405.

Obendorf PJ, Oxnard CE, Kefford BJ (2008): Are the small human-like fossils found on Flores human endemic cretins? Proc Biol Sci 275: 1287-1296.

Organ CL, Shedlock SM, Meade A, Pagel M, Edwards SV (2007): Origin of avian genome size and structure in non-avian dinosaurs. Nature 446:180-184.

Orme CD, Freckleton RP, Thomas GH, Petzoldt T, Fritz SA (2011): caper: Comparative Analyses of Phylogenetics and Evolution in R. http://R-Forge.R-project.org/projects/ caper/.
Pagel MD (1997): Inferring evolutionary processes from phylogenies. Zool Scr 26:331348.

- Pagel MD (1999): Inferring the historical patterns of biological evolution. Nature 401: 877-884.

- Pagel M, Meade A, Barker D (2004): Bayesian estimation of ancestral character states on phylogenies. Syst Biol 53:673-684.

R Development Core Team (2011): R: A Language and Environment for Statistical Computing. Vienna, R Foundation for Statistical Computing. http://www.R-project.org.

Richards G (2006): Genetic, physiologic and ecogeographic factors contributing to variation in Homo sapiens: Homo floresiensis reconsidered. J Evol Biol 19:1744-1767.

Rowe TB, Macrini TE, Luo ZX (2011): Fossil evidence on origin of the mammalian brain. Science 332:955-957.

-Safi K, Dechmann DK (2005): Adaptation of brain regions to habitat complexity: a comparative analysis in bats (Chiroptera). Proc Biol Sci 272:179-186.

- Safi K, Seid MA, Dechmann DK (2005): Bigger is not always better: when brains get smaller. Biol Lett 1:283-286.

- Schluter D, Price T, Mooers AO, Ludwig T (1997): Likelihood of ancestor states in adaptive radiation. Evolution 51:1699-1711.

Shultz S, Dunbar RIM (2010): Encephalization is not a universal macroevolutionary phenomenon in mammals but is associated with sociality. Proc Natl Acad Sci USA 107:2158221586.

Sigé B (1968): Les chiroptères du Miocène inférieur de Bouzigues. 1. Étude systématique. Palaeovertebrata 1:65-133.

-Sigé B, Crochet JY, Sudre J, Aguilar JP, Escarguel G (1997): Nouveaux sites d'âges variés dans les remplissages karstiques du Miocène inférieur de Bouzigues (Hérault, Sud de la France). 1. Sites et faunes 1 (Insectivores, Chiroptères, Artiodactyles). Geobios 30 (suppl 1):477-483.

Smaers JB, Vinicius L (2009): Inferring macroevolutionary patterns using an adaptive peak model of evolution. Evol Ecol Res 11:9911015.

Stampanoni M, Groso A, Isenegger A, Mikuljan G, Chen Q, Bertrand A, Henein S, Betemps R, Frommherz U, Bohler P, Meister D, Lange M, Abela R (2006): Trends in synchrotronbased tomographic imaging: the SLS experience; in Bonse (ed): Developments in X-Ray Tomography V, vol 6318, pp U199-U212. Proceedings of SPIE - The International Society for Optical Engineering.

Vannucci RC, Barron TF, Holloway RL (2011): Craniometric ratios of microcephaly and LB1, Homo floresiensis, using MRI and endocasts. Proc Natl Acad Sci USA 108:1404314048.

-Weber J, Czarnetzki A, Pusch CM (2005): Comment on 'The brain of LB1, Homo floresiensis'. Science 310:236. 